\title{
Common Germinal-Center B-Cell Origin of the Malignant Cells in Two Composite Lymphomas, Involving Classical Hodgkin's Disease and Either Follicular Lymphoma or B-CLL
}

\author{
Ralf Küppers, ${ }^{1,2}$ Ana B. Sousa, ${ }^{1}$ Audrey S. Baur, ${ }^{3}$ John G. Strickler, ${ }^{4}$ Klaus Rajewsky, ${ }^{1}$ \\ and Martin-Leo Hansmann ${ }^{5}$ \\ ${ }^{1}$ Institute for Genetics, University of Cologne, Cologne, Germany \\ ${ }^{2}$ Department of Internal Medicine I, University of Cologne, Cologne, Germany \\ ${ }^{3}$ Institute of Pathology, University Hospital, Lausanne, Switzerland \\ ${ }^{4}$ Allina Laboratories, Abbott Northwestern Hospital, Minneapolis, Minnesota, USA \\ ${ }^{5}$ Department of Pathology, University of Frankfurt, Frankfurt/Main, Germany \\ Contributed by K. Rajewsky. Accepted February 22, 2001
}

\begin{abstract}
Background: Classical Hodgkin's disease (HD) and B-cell non-Hodgkin lymphoma (NHL) occasionally occur in the same patient. Such composite lymphomas represent interesting models to study the pathogenesis of B-cell lymphomas and the relationship between HD and B-cell NHL. Materials and Methods: We analyzed two composite lymphomas (a combination of classical HD with follicular lymphoma [FL] and a combination of classical HD with Bcell chronic lymphocytic leukemia [B-CLL]) by micromanipulation of single cells from tissue sections and amplification of immunoglobulin $\mathrm{V}$ region genes for the clonal relationship of the tumor cells.

Results: In both cases, clonally related variable (V) genes with both shared as well as distinct somatic mutations were obtained from the two lymphomas, showing that in each of the cases the distinct tumor cells were
\end{abstract}

members of a common germinal center (GC) B-cell clone. FL cells from two different lymph nodes of patient 1 showed a similar mutation pattern, suggesting that infiltration of these lymph nodes by tumor cells was not restricted to a particular FL cell or subclone. In the FL, a single cell was identified with a mutation signature indicating that premalignant cells can persist in the tissue.

Conclusions: The cases presented here further underline the close relationship between HD and B-cell NHL and the role of the GC in lymphomagenesis. Whereas the latter was already suggested for FL and HD, the present study indicates that also in the B-CLL subset characterized by mutated Ig genes, important steps in malignant transformation happen in the GC, and that HRS cells can derive from CD5-positive B cells.

\section{Introduction}

Because immunoglobulin (Ig) variable (V) region genes are highly diverse and specific for B cells, they represent ideal molecular markers for B-lineage cells and the clonal composition of B-cell populations. Moreover, because the process of somatic hypermutation, which further diversifies $\mathrm{V}$ region genes in the course of T-cell-dependent immune responses, appears to be restricted to germinal center (GC) B cells (1), the presence and pattern of somatic mutations in $\mathrm{V}$ region genes is informative regarding the differentiation stage of the respective B cell (2).

Through analysis of rearranged Ig genes amplified from single, micromanipulated Hodgkin and Reed-

Address correspondence and reprint requests to: Ralf Küppers, University of Cologne, Department of Internal Medicine I, LFI E4 R706, Joseph-Stelzmannstr. 9, D-50931 Cologne, Germany. Phone: +49 221478 4490; Fax: +49 221478 6383; e-mail: rkuppers@mac.genetik.uni-koeln.de

R. Küppers and A.B. Sousa contributed equally to this work.
Sternberg (HRS) cells of Hodgkin's disease (HD) it has been established that, in the vast majority of cases, HRS cells derive from GC B cells (3-5). Only in rare cases does HD represent a T-cell lymphoma $(6,7)$.

Occasionally, HD and a B-cell non-Hodgkin lymphoma (NHL) occur in the same patient, either simultaneously or sequentially (8). Such lymphomas represent interesting models to study the pathogenesis of B-cell lymphomas and the relationship between HD and B-cell NHL. Four combinations of classical HD and B-cell NHL have previously been analyzed in detail by micromanipulation of single cells and amplification and sequence analysis of rearranged Ig genes (9-11). In one case with a B-cell NHL developing after HD, the two lymphomas were clonally unrelated (9). It is possible that the development of the B-cell NHL was caused by the radio- and chemotherapy that the patient received. In each of the three other cases, the HRS and B-NHL cells derived from a shared precursor, because clonally related Ig gene rearrangements were amplified from the two types of tumor cells $(10,11)$. 
In the present study, we analyzed cases representing a combination of either B-cell chronic lymphocytic leukemia (B-CLL) with classical HD, or a composite follicular lymphoma (FL) and HD. From the latter case, three distinct biopsy specimens (from two lymph nodes and the spleen) were analyzed. Clonal Ig heavy and light chain genes were amplified from each of the lymphomas.

\section{Materials and Methods}

Patients and Tissues

Patient 1 was a male born in 1953. Stomach, small bowel, and colon biopsies done in July 1996 showed FL. Exploratory laparotomy some days later showed composite FL and HD in a splenic hilar lymph node and HD in the spleen. The HD was of the mixed cellularity type. The patient developed a hemophagocytic syndrome and died about 3 weeks after laparotomy at the age of 43 . He never received any lymphoma therapy. Autopsy revealed FL in liver, small intestine, stomach, mesenteric nodes, thymus, and bone marrow. HD involved the liver and several lymph nodes (thoracic, retroperitoneal, and peripancreatic).

Patient 2 was an 81-year-old woman who was followed for a B-CLL diagnosed 5 years earlier. She developed cervical lymphadenopathies, presenting with fever and lymphocytosis. Flow cytometric analysis of the peripheral blood lymphocytes showed a monoclonal $\lambda$ light chain-expressing B-cell population positive for CD5 (weak), which was classified as B-CLL. A cervical lymphadenopathy was excised.

\section{Immunostaining and Micromanipulation}

For patient 1, molecular analysis was performed with three frozen biopsy specimens: a splenic hilar lymph node with composite lymphoma, a spleen biopsy with HD, and a mesenteric lymph node with FL. For patient 2, the molecular analysis was performed on a frozen biopsy specimen from the excised cervical lymph node.

Frozen or paraffin-embedded sections were stained for CD30 (BerH2, Dako, Hamburg, Germany), CD15 (LeuM1, Becton Dickinson, Heidelberg, Germany, or C3D-1, Hamburg, Germany) and CD20 (L26, Dako). Light chain expression was determined for both cases by flow cytometry, using a cell suspension of a fresh FL specimen of patient 1 , or peripheral blood of patient 2 . The tumor cells were analyzed for Epstein-Barr virus (EBV) by standard EBV-encoded RNA (EBER) in situ hybridization.

Five- to $10-\mu \mathrm{m}$ thick frozen tissue sections were stained either with anti-CD30 antibody for the isolation of HRS cells, anti-CD20 antibody for the isolation of B-CLL or FL B cells, or anti-CD3 antibody for the isolation of $\mathrm{T}$ cells from case 1 . Bound antibody was visualized using alkaline phosphatase and Fast Red. Single cells were micromanipulated with a hydraulic micromanipulator (12). For B-CLL cells, two cells were put into each reaction tube.
From each section used for micromanipulation, aliquots of the buffer covering the sections were aspirated and used as negative controls in the polymerase chain reaction (PCR).

\section{Single-Cell PCR}

Before Ig gene-specific PCR was carried out, the genomic DNA of single cells was preamplified by whole genome amplification (13), using proteinase $\mathrm{K}$ digestion $\left(2 \mathrm{hr}\right.$ at $50^{\circ} \mathrm{C}$ with $0.15 \mathrm{mg} / \mathrm{mL}$ of the enzyme) to release proteins from the DNA. Aliquots $(4 \mu \mathrm{L})$ of this reaction were then used for Ig gene-specific PCR. Rearranged Ig heavy and light chain genes were amplified in a semi-nested PCR as described (14). For the amplification of IgH genes, either $\mathrm{V}_{\mathrm{H}}$ leader or framework region (FR) I family-specific primers were used together with $\mathrm{J}_{\mathrm{H}}$ primer mixes. $\mathrm{V}_{\kappa}$ and $\mathrm{V}_{\lambda}$ gene rearrangements were amplified using FRI family-specific primers together with the corresponding $\mathrm{J}$ primer mixes. PCR products were gel purified and directly sequenced on an automatic sequencer (ABI377, PE Biosystems), using the primers of the second round of PCR for sequencing.

\section{Results}

Histologic and Phenotypic Analysis of the Cases

In patient 1 , the HD in the spleen and splenic hilar lymph node showed a histologic picture typical for mixed cellularity HD (Fig. 1). Diagnosis of classical HD is further corroborated by positivity of HRS cells for CD30 and CD15 and lack of CD20 expression (Table 1 and Fig. 1). The FL cells in a mesenteric lymph node and the splenic hilar lymph node that also showed HD infiltration are CD30 and CD15 negative, but CD20 positive (Table 1). The FL cells in the mesenteric lymph node were stained for CD10 and found to be positive, as is typical for FL (data not shown). A flow cytometric analysis of a cell suspension from the FL showed $\kappa$ light chain expression of the tumor cells.

In case 2, the lymph node architecture was diffusely effaced by a small lymphocytic lymphoma of the B-CLL type (Fig. 1). Admixt with the B-CLL were small islands of classic HD containing typical HRS cells in a histiocyte- and lymphocyte-rich background (Fig. 1). The HRS cells, which were often surrounded by T-cell rosettes, expressed CD30 and partially CD15, but lack CD20 and CD5 expression (Table 1 and Fig. 1). The B-CLL cells were negative for CD30 and CD15, but CD20 positive (Fig. 1). No cytoplasmic light chain expression was found by immunohistochemistry in the B-CLL cells on paraffin sections, ruling out an immunocytoma. B-CLL was also diagnosed in the peripheral blood, and flow cytometric analysis of B-CLL cells in the peripheral blood demonstrated $\lambda$ light chain positivity on their surface and weak CD5 coexpression.

In both cases, EBER in situ hybridization revealed absence of EBV from the B-cell NHL and HRS cells. 

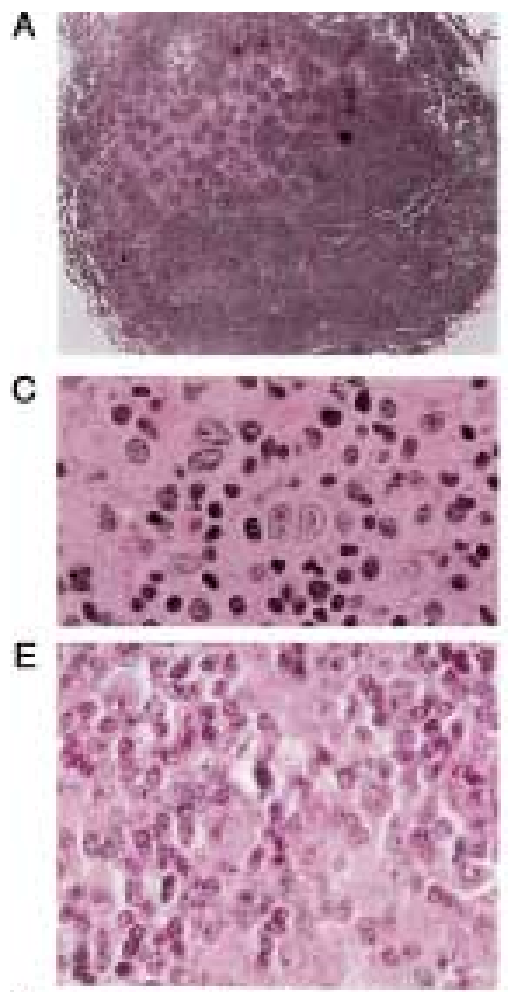

G
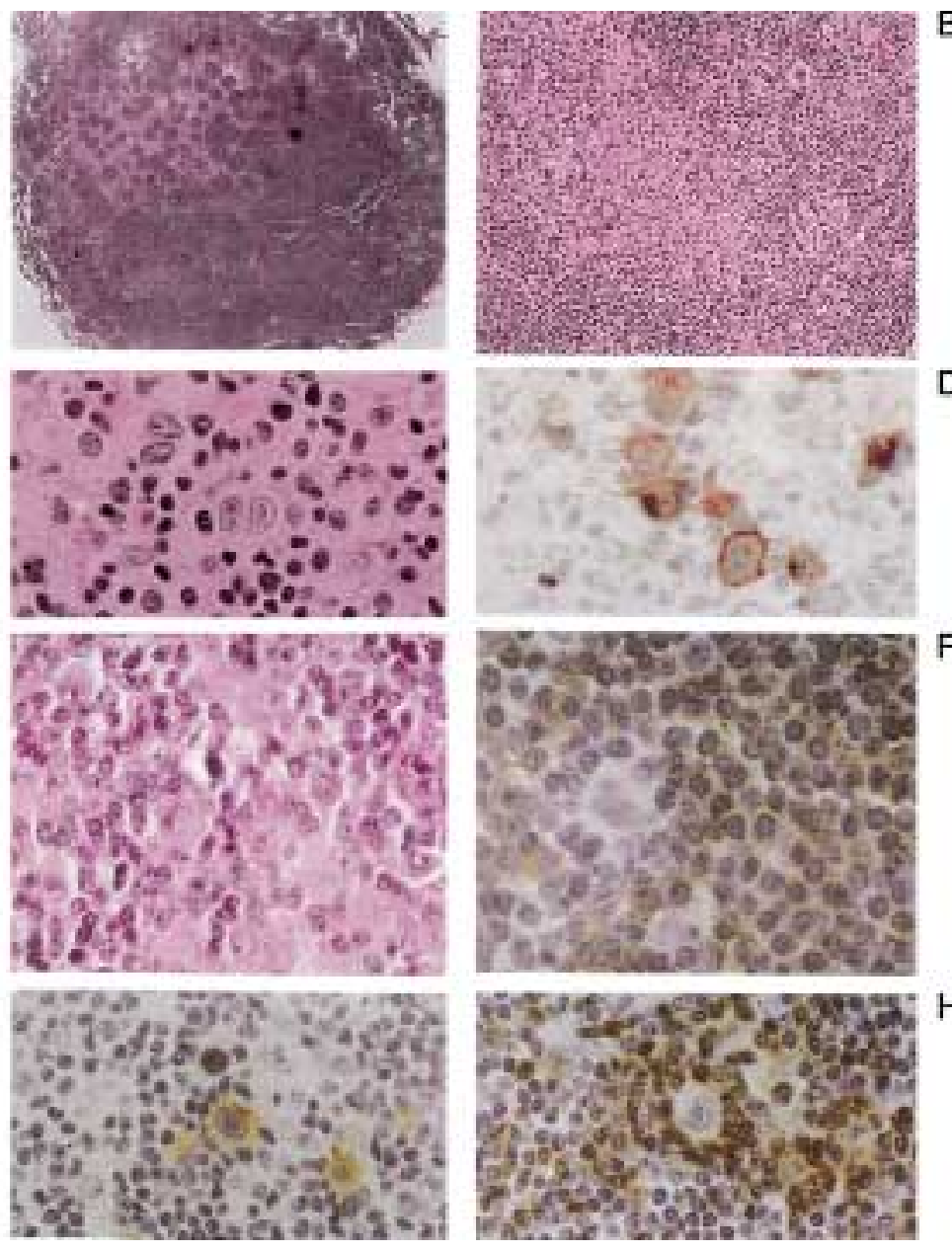

B

Fig. 1. Histology and immunohistology of the two composite lymphomas. (A) to (D) case l; (E) to $(\mathrm{H})$ case 2 . (A) Mesenteric lymph node infiltrated by follicular lymphoma showing numerous neoplastic

$F$ follicles. (Hematoxilin $\&$ eosin staining, $0.5 \times$.) (B) Combination of FL and HD. Infiltrates of the B-cell NHL on the top, bottom and right side of the picture. Mainly in the middle and on the left top an infiltrate of HD composed of small lymphocytes, histiocytes, epitheloid cells and a Hodgkin cell. (Hematoxilin \& eosin staining, $20 \times$.) (C) Infiltrate of HD showing a Reed-Sternberg cell in the middle of the picture. The other part of the hilar lymph node (not shown here) is infiltrated by a FL. (Hematoxilin $\&$ eosin staining, $40 \times$.) (D) HRS cells of the combination of HD and FL showing a positive immunostaining with CD 15, 40 $\times$. (E) HRS cells on a background rich in lymphocytes and histiocytes, hematoxilin $\delta$ eosin staining, $150 \times$. (F) Diffuse areas with CD20positive B-CLL cells surrounding small islands with HRS cells $(180 \times)$. (G) Part of the HRS cells express CD15 (120 $\times)$. (H) CD3 staining. The HD islands contain mainly CD3-positive $\mathrm{T}$ cells, with formation of rosettes around HRS cells $(120 \times)$.
PCR Analysis of Single Micromanipulated Cells for $V_{H}, V_{\kappa}$, and $V_{\lambda}$ Gene Rearrangements

For patient 1, CD30-positive HRS cells were micromanipulated from the spleen and a splenic hilar lymph node. The former biopsy showed only HD involvement, whereas the latter biopsy presented as a composite lymphoma of HD and FL. Consequently, FL B cells $\left(\mathrm{CD} 20^{+}\right)$were isolated from the splenic hilar lymph node, and also from a mesenteric lymph node that showed only infiltration of FL. A total of
36 HRS cells ( 21 from the splenic hilar lymph node and 15 form the spleen) were analyzed for $V_{H}$ and $V_{\kappa}$ gene rearrangements. A clonal $\mathrm{V}_{\mathrm{H}}$ and a clonal $\mathrm{V}_{\kappa}$ gene rearrangement was obtained from 19 and 5 of the cells, respectively (Table 2). The rearrangements amplified from HRS cells of the two distinct biopsies were identical. The $\mathrm{V}_{\mathrm{H}}$ and the $\mathrm{V}_{\kappa}$ gene rearrangement were both in frame and potentially functional (Table 3). Ten HRS cells analyzed for $\mathrm{V}_{\lambda}$ gene rearrangements were all negative (Table 2). From 35

Table 1. Phenotype of HRS and B NHL cells of two composite lymphomas

\begin{tabular}{clcccccc}
\hline Case & \multicolumn{1}{c}{ Cell Type } & CD30 & CD15 & CD20 & CD5 & sIgL & EBV \\
\hline \multirow{2}{*}{1} & HRS & + & + & - & nd & nd & - \\
& follicular lymphoma & - & - & + & nd & $\kappa++^{*}$ & - \\
2 & HRS & + & partly & - & - & nd & - \\
& B-CLL & - & - & & $+(\text { low })^{*}$ & $\lambda+*$ & - \\
\hline
\end{tabular}

*Determined by flow cytometry (using peripheral blood in case 2);

\#determined by in situ hybridization; nd: not done. 
Table 2. PCR and sequence analysis of $\mathrm{V}$ gene rearrangements of single HRS and B-NHL tumor cells from two composite lymphomas

\begin{tabular}{|c|c|c|c|c|c|c|}
\hline Case & Biopsy & Cell Type & V Gene & $\begin{array}{l}\text { No. of Positive } \\
\text { Samples/Total }\end{array}$ & $\begin{array}{c}\text { PCR } \\
\text { Products }\end{array}$ & $\begin{array}{c}\text { Repeated } \\
\text { Rearragements }\end{array}$ \\
\hline \multirow[t]{10}{*}{1} & Splenic & HRS & VH & $13 / 21$ & 13 & 13 \\
\hline & Hilar & & $\mathrm{V} \kappa$ & $4 / 21$ & 4 & 4 \\
\hline & Lymph node & & $\mathrm{V} \lambda$ & $0 / 10$ & & \\
\hline & & FL & VH & $8 / 20$ & 8 & 8 \\
\hline & & & $\mathrm{V} \kappa$ & $4 / 20$ & 4 & 4 \\
\hline & & & $\mathrm{V} \lambda$ & $0 / 10$ & & \\
\hline & Spleen & HRS & VH & $6 / 15$ & 6 & 6 \\
\hline & & & $\mathrm{V} \kappa$ & $1 / 15$ & 1 & 1 \\
\hline & Mesenteric & FL & VH & $6 / 15$ & 6 & 6 \\
\hline & Lymph node & & $\mathrm{V} \kappa$ & $7 / 15$ & 7 & 7 \\
\hline \multirow[t]{7}{*}{2} & Cervical & HRS & VH & $6 / 25$ & 6 & 6 \\
\hline & Lymph node & & $\mathrm{V} \kappa$ & $0 / 5$ & & \\
\hline & & & $\mathrm{V} \lambda$ & $10 / 25$ & 10 & 10 \\
\hline & & $\mathrm{B}-\mathrm{CLL}^{+}$ & VH & $4 / 15$ & 4 & 4 \\
\hline & & & $\mathrm{V} \kappa$ & $0 / 2$ & & \\
\hline & & & $\mathrm{V} \lambda$ & $4 / 15$ & 4 & 4 \\
\hline & Controls* & & & & & \\
\hline \multirow[t]{5}{*}{1} & $\mathrm{~T}$ cells & & VH & $0 / 14$ & & \\
\hline & & & $\mathrm{V} \kappa$ & $0 / 14$ & & \\
\hline & Buffer & & VH & $0 / 20$ & & \\
\hline & & & $\mathrm{V} \kappa$ & $0 / 20$ & & \\
\hline & & & $\mathrm{V} \lambda$ & $0 / 6$ & & \\
\hline \multirow[t]{3}{*}{2} & Buffer & & $\mathrm{VH}$ & $0 / 13$ & & \\
\hline & & & $\mathrm{V} \kappa$ & $0 / 3$ & & \\
\hline & & & $\mathrm{V} \lambda$ & $0 / 13$ & & \\
\hline
\end{tabular}

*Summary of controls with samples of buffer covering the sections. In addition, a total of 26 controls without added cells or buffer from the sections was analysed as further negative controls, resulting in only one positive sample with three unique $V_{\kappa} J_{\kappa}$ joints.

${ }^{\#} T$ The clonal $\mathrm{V}_{\mathrm{H}}$ and $\mathrm{V}_{\kappa}$ genes from the distinct locations and the distinct lymphoma cells of a case are clonally related.

${ }^{\dagger}$ Each sample contained two cells.

$\mathrm{CD}^{+} \mathrm{O}^{+} \mathrm{B}$ cells isolated from the two lymph nodes involved with $\mathrm{FL}, 14$ clonal $\mathrm{V}_{\mathrm{H}}$ region genes and 11 clonal $\mathrm{V}_{\kappa}$ region genes were amplified (Table 2). These rearrangements were (with the exception of distinct somatic mutations; see below) identical to the ones amplified from the HRS cells (Table 3), showing that the two lymphomas are clonally related. No $V_{\lambda}$ gene rearrangement was amplified from any of 10 cells analyzed. No amplificates were obtained from any of the buffer controls or from $14 \mathrm{~T}$ cells micromanipulated from a CD3-stained tissue section of the splenic hilar lymph node (Table 2).

For patient 2 with a combination of classical HD and B-CLL, 25 micromanipulated CD $30^{+}$HRS cells were analyzed for $V_{H}$ and $V_{\lambda}$ gene rearrangements. A clonal $V_{\mathrm{H}}$ gene rearrangement was amplified from 6 and a clonal $V_{\lambda}$ rearrangement from 10 of the cells (Table 2). Both rearrangements are in frame and potentially functional. No PCR products were obtained from 5 cells analyzed for $V_{\kappa} J_{\kappa}$ joints. The lack of $V_{\kappa}$ gene rearrangement in this clone is not unusual, because $\mathrm{V}_{\kappa} \mathrm{J}_{\kappa}$ joints are frequently deleted in $\lambda$ expressing B cells (15). Because PCR efficiency is usually lower for small lymphocytes compared to the large and often multinucleated HRS cells, and because we did not expect to find intraclonal variation among B-CLL cells (see below), two micromanipulated B-CLL cells were always put into a reaction tube for PCR analysis. Fifteen of these samples were analyzed for $V_{H}$ and $V_{\lambda}$ gene rearrangements. Four $V_{H}$ and four $V_{\lambda}$ genes were obtained. Like in patient 1, these rearrangements were (with the exception of distinct somatic mutations; see below) identical to the ones amplified from the HRS cells (Table 3), showing that also in this case, the two lymphomas are clonally related. Two samples analyzed for $\mathrm{V}_{\kappa}$ rearrangements were both negative.

\section{Analysis of Somatic Mutation Patterns}

The $\mathrm{V}_{\mathrm{H}}$ and $\mathrm{V}_{\kappa}$ gene rearrangements of the HRS cells from patient 1 were somatically mutated, with mutation frequencies of $11.7 \%$ and $9.1 \%$, respectively (Table 3). The sequences amplified from the HRS 
Table 3. V gene sequence and mutation analysis of Ig gene rearrangements from HRS and B-NHL cells of two composite lymphomas

\begin{tabular}{|c|c|c|c|c|c|c|c|}
\hline Case & Source of Cells & $\begin{array}{c}\text { V Gene } \\
\text { (V Family) }\end{array}$ & $\begin{array}{l}\text { Potentially } \\
\text { Functional }\end{array}$ & $\begin{array}{c}\text { Mutation } \\
\text { Frequency }(\%)\end{array}$ & $\begin{array}{l}\text { Lymphomas } \\
\text { Clonally Related }\end{array}$ & $\begin{array}{l}\text { Intraclonal } \\
\text { Diversity }\end{array}$ & $\begin{array}{c}\text { Samples With } \\
\text { Sequence Variation* }\end{array}$ \\
\hline \multirow[t]{5}{*}{1} & Hodgkin's disease & V3-23 (VH3) & Yes & 11.7 & \multirow{5}{*}{ Yes } & No & $-/ 19$ \\
\hline & & $\mathrm{A} 27(\mathrm{~V} \kappa 3)$ & Yes & 9.1 & & No & -15 \\
\hline & & & & & & & \\
\hline & Follicular lymphoma & V3-23 (VH3) & Yes & $10.3^{\#}$ & & Yes & $14 / 14$ \\
\hline & & $\mathrm{A} 27(\mathrm{~V} \kappa 3)$ & Yes & $7.4^{\#}$ & & Yes & $10 / 11$ \\
\hline \multirow[t]{5}{*}{2} & Hodgkin's disease & Vl-2 (VH1) & Yes & 2.1 & \multirow{5}{*}{ Yes } & No & $-/ 6$ \\
\hline & & $\mathrm{V} 2-14(\mathrm{~V} \lambda 2)$ & Yes & 1.5 & & No & $-/ 10$ \\
\hline & & & & & & & \\
\hline & B-CLL & Vl-2 (VHI) & Yes & 2.3 & & No & $-/ 4$ \\
\hline & & $\mathrm{V} 2-14(\mathrm{~V} \lambda 2)$ & Yes & 0.8 & & No & $-/ 4$ \\
\hline
\end{tabular}

*Number of variations per total number. The dash indicates that all sequences are identical.

\#Considering only shared mutations.

$\mathrm{V}$ gene sequences have been submitted to the EMBL data library (accession numbers AJ 409167-AJ409197).

cells of the splenic biopsy and the splenic hilar lymph node were identical, and no intraclonal sequence diversity was observed. The corresponding rearrangements from the FL showed extensive intraclonal variation. All 14 of the $V_{H}$ genes and 10 of the $11 V_{K}$ genes differed by one or more somatic mutations from each other. Considering only the shared mutations, the mutation frequencies for the $\mathrm{V}_{\mathbf{H}}$ and $\mathrm{V}_{\kappa}$ genes of the FL are $10.3 \%$ and $7.4 \%$, respectively (Table 3). For the heavy chain, in the region from complementarity determining region (CDR)I to CDRIII, 26 mutations were shared between the HRS and FL cells, whereas there were 7 additional mutations in the HRS-cell sequences and 3 additional shared mutations in the heavy chain sequences of the FL cells (Fig. 2A). A similar situation with shared as well as distinct somatic mutations was also seen for the $\mathrm{V}_{\kappa}$ light chain genes (data not shown). When the mutation pattern of the FL cells isolated from the mesenteric and splenic hilar lymph nodes were compared, no tissue-specific mutations were observed. Surprisingly, I B cell from the splenic hilar lymph node (BC12) harbored in its $\mathrm{V}_{\mathrm{H}}$ gene only 17 of the 26 somatic mutations carried by the presumptive shared precursor of the HRS and FL cells, and 15 unique mutations (Fig. 2A). Thus, this B cell likely derives from a precursor of the putative shared tumor cell precursor, indicating persistence of a premalignant cell in the tissue.

In patient 2, the $\mathrm{V}$ genes were less mutated. The $V_{H}$ and $V_{\lambda}$ gene rearrangements amplified from the HRS cells were mutated with frequencies of $2.1 \%$ and $1.5 \%$, respectively (Table 3 ). The corresponding rearrangements of the B-CLL had mutation frequencies of $2.3 \%$ and $0.8 \%$. As expected, neither in the HRS nor in the B-CLL cells was any ongoing somatic mutation observed. Comparing the mutation patterns of the clonally related $\mathrm{V}_{\mathrm{H}}$ genes from the two lymphomas, 5 mutations were shared, whereas 2 mutations were present only in the HRS cells and 3 only in the B-CLL cells (Fig. 2B). A similar pattern was observed for the light chain genes (Fig. 2B). Although the mutation load in case 2 is relatively low, the fact that all mutations were obtained repeatedly (thus ruling out PCR-introduced errors) and that distinct mutation patterns were obtained for the two related lymphoma clones, strongly argues for a GC $\mathrm{B}$-cell origin of the shared tumor precursor (see below). Moreover, although the average mutation load of human tonsillar GC B cells is in the range of $6 \%$, numerous GC B cell clones in human lymph nodes with $2-3 \%$ mutation have been observed $(12,16)$.

\section{Discussion}

Common B-Cell Precursors in Two Composite Lymphomas and the Role of the GC in Their Development

In the two composite lymphomas analyzed in the present study, the molecular Ig gene analysis revealed that in each case, the HRS and B-NHL cells were clonally related. Moreover, the presence of shared as well as distinct somatic mutations in the rearranged Ig genes indicates that in both cases the common precursor was a GC B cell (Fig. 2C). This situation is reminiscent of three other combinations of classical HD and B-cell NHL previously described (two composite lymphomas of HD and FL, and one case of a T-cell-rich B-cell lymphoma followed 3 years later by classical HD), because also in these cases the lymphomas derived from common precursors, and the lymphomas harboured shared as well as distinct V gene mutations $(10,11)$. Thus, among composite lymphomas, clonal relationship of the distinct tumors appears to be the rule rather than the exception. 

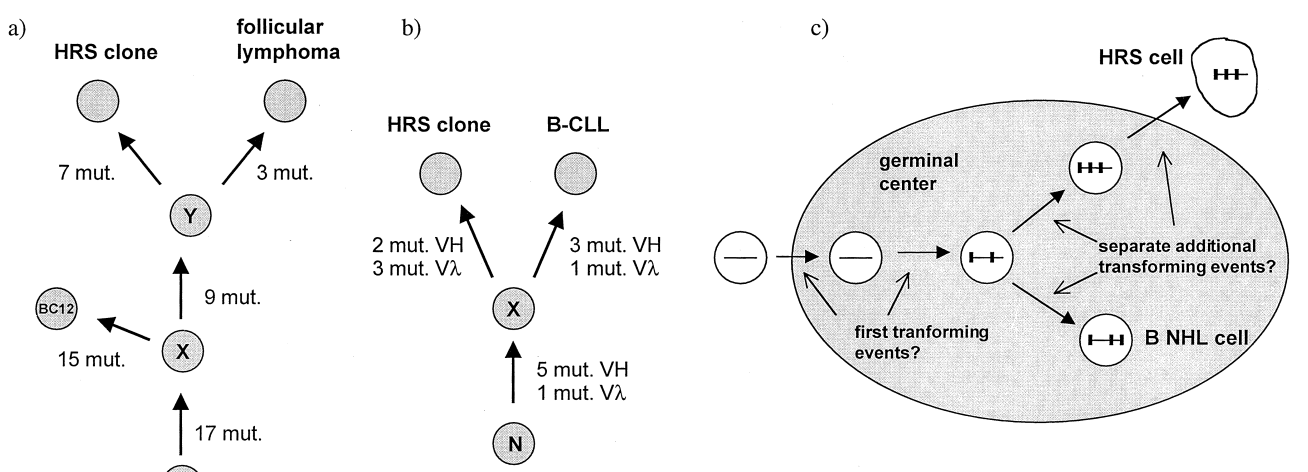

Fig. 2. Genealogical trees of somatic mutation patterns and scenario for the generation of composite lymphomas.

(A) Genealogical tree showing the relationship between the HRS cell clone, the FL and the presumptive premalignant B cell (BC12) belonging to the same clone in patient 1 . The tree is based on the $\mathrm{V}_{\mathrm{H}}$ sequences. A similar and compatible pattern is seen for the clonal $V_{\kappa}$ gene rearrangements of the cells (not shown). " $\mathrm{N}$ " denotes the presumptive naive founder $\mathrm{B}$ cell of the clone, " $\mathrm{X}$ " and " $\mathrm{Y}$ " denote hypothetical intermediates in the clonal evolution of the subclones. The number of somatic mutations (mut.) in the development of the clone members is given. For the FL, only shared mutations are considered. (B) Genealogical tree showing the relationship between the HRS cell and B-CLL clone in patient 2 . The tree is based on the $\mathrm{V}_{\mathrm{H}}$ and $\mathrm{V}_{\lambda}$ sequences. "N" denotes the presumptive naive founder B cell of the clone, " $\mathrm{X}$ " denotes the hypothetical shared precursor of the lymphoma clones. The number of somatic mutations (mut.) in the development of the clone members is given. (C) Scenario for composite lymphoma generation (11). Horizontal lines in the cells indicate rearranged Ig genes, vertical lines represent somatic mutations.

Because it appears highly unlikely that two lymphomas independently develop from two members of a B-cell clone, one may assume that the shared precursor of the two lymphomas already carried one or more transforming events. On the other hand, the fact that two histologically and clinically different lymphomas develop from a common precursor may indicate that also different transforming events are involved in the pathogenesis of these lymphomas (Fig. 2C) (11). Another factor that may influence the type of malignancy developing from a transformed GC B cell may relate to the subset of GC B cell that the tumor precursor belongs to. For example, it is generally assumed that FL develops from a transformed mutating and antigen-selected GC B cell $(17,18)$, whereas HRS cells in classical HD appear to derive from preapoptotic GC B cells $(3,4)$. Hence, premalignant members of a common GC B-cell clone at distinct differentiation stages (e.g., antigen-selected versus preapoptotic) may have different potentials to develop into a particular type of B-cell lymphoma.

\section{Tumor Cell Dissemination and Clonal}

\section{Heterogeneity in a FL}

From patient 1, two different lymph nodes infiltrated by FL were analyzed. As is typical for FL $(17,18)$, extensive ongoing somatic mutation was observed among the members of the tumor clone (Table 3). The mutation pattern of the rearranged Ig genes did not reveal any somatic mutations that were specific for the FL cells of only one of the two different lymph nodes. Thus, it appears that dissemination of the lymphoma in the two lymph nodes was not initiated by a single or few lymphoma cells, but more likely by massive infiltration by many tumor cells.
Another perhaps surprising finding in case 1 was the identification of a B cell clonally related to the composite lymphoma, but with a mutation signature indicating that this cell represents a progeny of a precursor of the shared lymphoma precursor (Fig. 2A). Therefore, this cell (BC12) is not a member of either of the two lymphoma clones, but more likely a premalignant $\mathrm{B}$ cell that persisted in the tissue. It is, however, unclear whether $\mathrm{BC} 12$ represents a "normal" B cell of the common GC cell clone, or whether already the shared precursor of $\mathrm{BC} 12$ and the two lymphoma clones harbored a transforming event. An attempt to identify more cells resembling $\mathrm{BC} 12$ using primers specific for the $\mathrm{V}_{\mathrm{H}}$ gene sequence of this cell and genomic DNA isolated from an adjacent tissue section failed (data not shown).

\section{The Relationship Between B-CLL and HD}

Two subtypes of B-CLL have been described, one developing from B cells with unmutated Ig genes and one from cells with mutated Ig genes (GC or memory B cells) (19-21). This distinction is biologically and clinically relevant, because the two subsets show different types of chromosomal abnormalities and a significantly different prognosis (20-22). It is presently unclear at which stage of B-cell development malignant transformation of the B-CLL precursors occurs. For the case of B-CLL and HD analyzed in the present study, the mutation pattern of the Ig genes indicates that the shared tumor precursor carried or acquired transforming events while residing in the GC. Thus, like for many other types of B cell lymphomas (23), lymphomagenesis may (at least partly) occur in the GC for the B-CLL subset with mutated Ig genes as well. 
Three combinations of B-CLL with HD (two cases classified as Richter's syndrome with HD features developing after B-CLL, and one composite lymphoma) have previously been analyzed by Ohno et al. (24). In two cases, a common clonal origin was observed; failure to amplify Ig gene rearrangements from the HRS cells left the question of a common origin of the tumor cells open for the third case. Thus, a clonal relationship between a BCLL and an associated HD is not a rare event. However, because only very short sequence fragments were amplified, the presence of somatic mutations could not be analyzed, so that the question of a potential GC B-cell origin was not addressed in that work.

In a previous study we analyzed three cases of B-CLL with intermingled HRS-like cells, which were not classified as composite lymphomas of HD and B-CLL, because the HRS-like cells were not found in a typical mixed cellular infiltrate. In two of the cases, the HRS-like cells represented clones unrelated to the B-CLL (14). In these cases, the HRS-like cells carried EBV, pointing to a role of the virus in clonal expansion of an EBV-infected cell in the setting of a B-CLL. In the third case, however, the B-CLL was clonally related to the HRS-like cells, and the detection of shared as well as distinct somatic mutations indicated that both clones represent descendents of a shared precursor. Based on this observation, we speculated that perhaps such clones of HRS-like cells in B-CLL may occasionally progress to typical HD cases. The clonal relationship of the B-CLL and HD in patient 2 of the present study supports this idea. Moreover, it is noteworthy that patient 2 was first diagnosed with B-CLL 5 years before the composite lymphoma developed. On the basis of the clonal relationship between the B-CLL and HRS cell clones, this indicates that (a precursor of) the HRS tumor clone resided in the patient for several years before it gave rise to clinically apparent HD. Evidence that (premalignant?) precursors of the B-CLL tumor clone can indeed persist as expanded clones for long time besides the B-CLL, has been provided previously by Dono et al. (25).

$\mathrm{B}-\mathrm{CLL}$ is regarded as a malignancy of CD5 B cells (26), whereas most other B-cell NHL derive from conventional B cells. If this assumption is true, the finding that cases of classical HD can be clonally related to lymphomas of conventional B cells (like follicular lymphoma) or to CD5-positive B-CLL suggests that HRS cells in classical HD can derive from both types of B-lineage cells.

\section{Acknowledgments}

We thank Michaela Fahrig and Julia Jesdinsky for excellent technical assistance; Andreas Bräuninger for support and discussion; and Nick Chiorazzi for valuable comments on the manuscript. This work was supported by the Deutsche Forschungsgemeinschaft through SFB502 and a Heisenberg stipend to R.K., and by the Deutsche Krebshilfe, Dr. Mildred Scheel Stiftung. A.B.S. is supported by the Programa PRAXIS-F.C.T. Portugal and the Gulbenkian Foundation.

\section{References}

1. Rajewsky K. (1996) Clonal selection and learning in the antibody system. Nature 381: 751-758.

2. Klein U, Goossens T, Fischer M, et al. (1998) Somatic hypermutation in normal and transformed human B cells. Immunol. Rev. 162: 261-280.

3. Kanzler H, Küppers R, Hansmann ML, Rajewsky K. (1996) Hodgkin and Reed-Sternberg cells in Hodgkin's disease represent the outgrowth of a dominant tumor clone derived from (crippled) germinal center B cells. J. Exp. Med. 184: 14951505.

4. Küppers R, Rajewsky K. (1998) The origin of Hodgkin and Reed/Sternberg cells in Hodgkin's disease. Annu. Rev. Immunol. 16: 471-493.

5. Marafioti T, Hummel M, Foss H-D, et al. (2000) Hodgkin and Reed-Sternberg cells represent an expansion of a single clone originating from a germinal center B-cell with functional immunoglobulin gene rearrangements but defective immunoglobulin transcription. Blood 95: 1443-1450.

6. Müschen M, Rajewsky K, Bräuninger A, et al. (2000) Rare occurrence of classical Hodgkin's disease as a T cell lymphoma. J. Exp. Med. 191: 387-394.

7. Seitz V, Hummel M, Marafioti T, Anagnostopoulos I, Assaf C, Stein H. (2000) Detection of clonal T-cell receptor gammachain gene rearrangements in Reed-Sternberg cells of classic Hodgkin disease. Blood 95: 3020-3024.

8. Jaffe ES, Müller-Hermelink K. Relationship between Hodgkin's disease and non-Hodgkin's lymphomas. In: Mauch PM, Armitage JO, Diehl V, Hoppe RT, Weiss LM, eds. Hodgkin's disease. Philadelphia: Lippincott Williams $\delta$ Wilkins, 1999, pp. 181-193.

9. Ohno T, Trenn G, Wu G, Abou-Elella A, Reis HE, Chan WC. (1998) The clonal relationship between nodular sclerosis Hodgkin's disease with a clonal Reed-Sternberg cell population and a subsequent B-cell small noncleaved cell lymphoma. Mod. Pathol. 11: 485-490.

10. Marafioti T, Hummel M, Anagnostopoulos I, Foss HD, Huhn D, Stein H. (1999) Classical Hodgkin's disease and follicular lymphoma originating from the same germinal center B cell. J. Clin. Oncol. 17: 3804-3809.

11. Bräuninger A, Hansmann ML, Strickler JG, et al. (1999) Identification of common germinal-center B-cell precursors in two patients with both Hodgkin's disease and non-Hodgkin's lymphoma. N. Engl. J. Med. 340: 1239-1247.

12. Küppers R, Zhao M, Hansmann ML, Rajewsky K. (1993) Tracing B cell development in human germinal centres by molecular analysis of single cells picked from histological sections. ЕMBO J. 12: 4955-4967.

13. Zhang L, Cui X, Schmitt K, Hubert W, Navidi W, Arnheim N. (1992) Whole genome amplification from a single cell: implication for genetic analysis. Proc. Natl. Acad. Sci. USA 89: 58475851.

14. Kanzler H, Küppers R, Helmes S, et al. (2000) Hodgkin and Reed-Sternberg-like cells in B-cell chronic lymphocytic leukemia represent the outgrowth of single germinal-center B-cell-derived clones: potential precursors of Hodgkin and Reed-Sternberg cells in Hodgkin's disease. Blood 95: 10231031.

15. Graninger WB, Goldman PL, Morton CC, O'Brien SJ, Korsmeyer SJ. (1988) The kappa-deleting element. J. Exp. Med. 167: 488-501.

16. Roers A, Hansmann ML, Rajewsky K, Küppers R. (2000) Single-cell PCR analysis of T helper cells in human lymph node germinal centers. Am. J. Pathol. 156: 1067-1071. 
17. Bahler DW, Levy R. (1992) Clonal evolution of a follicular lymphoma: evidence for antigen selection. Proc. Natl. Acad. Sci. USA 89: 6770-6774.

18. Cleary ML, Meeker TC, Levy S, et al. (1986) Clustering of extensive somatic mutations in the variable region of an immunoglobulin heavy chain gene from a human B cell lymphoma. Cell 44: 97-106.

19. Fais F, Ghiotto F, Hashimoto S, et al. (1998) Chronic lymphocytic leukemia B cells express restricted sets of mutated and unmutated antigen receptors. J. Clin. Invest. 102: 1515-1525.

20. Hamblin TJ, Davis Z, Gardiner A, Oscier DG, Stevenson FK. (1999) Unmutated Ig V(H) genes are associated with a more aggressive form of chronic lymphocytic leukemia. Blood 94: 1848-1854.

21. Damle RN, Wasil T, Fais F, et al. (1999) Ig V gene mutation status and CD38 expression as novel prognostic indicators in chronic lymphocytic leukemia. Blood 94: 1840-1847.
22. Oscier DG, Thompsett A, Zhu D, Stevenson FK. (1997) Differential rates of somatic hypermutation in $\mathrm{V}(\mathrm{H})$ genes among subsets of chronic lymphocytic leukemia defined by chromosomal abnormalities. Blood 89: 4153-4160.

23. Küppers R, Klein U, Hansmann M-L, Rajewsky K. (1999) Cellular origin of human B-cell lymphomas. N. Engl. J. Med. 341: 1520-1529.

24. Ohno T, Smir BN, Weisenburger DD, Gascoyne RD, Hinrichs SD, Chan WC. (1998) Origin of the Hodgkin/Reed-Sternberg cells in chronic lymphocytic leukemia with "Hodgkin's transformation." Blood 91: 1757-1761.

25. Dono M, Hashimoto S, Fais F, et al. (1996) Evidence for progenitors of chronic lymphocytic leukemia B cells that undergo intraclonal differentiation and diversification. Blood 87: 15861594.

26. Pritsch O, Maloum K, Magnac C, et al. (1997) What do chronic B cell malignancies teach us about B cell substs? Chem. Immunol. 67: 85-101. 